\title{
BMJ Open A cross-sectional exploration of the clinical characteristics of disengaged (NEET) young people in primary mental healthcare
}

\author{
Bridianne O'Dea, ${ }^{1}$ Nicholas Glozier, ${ }^{1}$ Rosemary Purcell, ${ }^{2}$ Patrick D McGorry, ${ }^{3}$ \\ Jan Scott, ${ }^{4}$ Kristy-Lee Feilds, ${ }^{1}$ Daniel F Hermens, ${ }^{1}$ John Buchanan, ${ }^{1}$ \\ Elizabeth M Scott, ${ }^{5}$ Alison R Yung, ${ }^{6}$ Eoin Killacky, ${ }^{3}$ Adam J Guastella, ${ }^{1}$ \\ Ian B Hickie ${ }^{1}$
}

To cite: O'Dea B, Glozier N, Purcell $\mathrm{R}$, et al.

A cross-sectional exploration of the clinical characteristics of disengaged (NEET) young people in primary mental healthcare. BMJ Open 2014:4:e006378.

doi:10.1136/bmjopen-2014006378

- Prepublication history for this paper is available online. To view these files please visit the journal online (http://dx.doi.org/10.1136/ bmjopen-2014-006378).

Received 15 August 2014 Revised 25 November 2014 Accepted 1 December 2014

\section{CrossMark}

For numbered affiliations see end of article.

\section{Correspondence to}

Bridianne O'Dea;

bridianne.odea@sydney.edu. au

\section{ABSTRACT}

Objective: Youth with mental health problems often have difficulties engaging in education and employment. In Australia, youth mental health services have been widely established with a key aim of improving role functioning; however, there is little knowledge of those who are not engaged in employment, education or training (NEET) and the factors which may influence this. This study aimed to examine NEET status and its correlates in a sample of such youth.

Design: Cross-sectional data from a longitudinal cohort study.

Setting: Between January 2011 and August 2012, young people presenting to one of the four primary mental health centres in Sydney or Melbourne were invited to participate.

Participants: Young adults ( $\mathrm{N}=696)$ aged between 15 and 25 years $(M=19.0, S D=2.8), 68 \%$ female, $58 \%$ $(n=404)$ attended headspace in Sydney.

Measures: Individuals 'Not in any type of Education, Employment or Training' in the past month were categorised as NEET. Demographic, psychological and clinical factors alongside disability and functioning were assessed using clinical interview and self-report.

Results: A total of $19 \%$ ( $n=130 / 696)$ were NEET. NEETs were more likely to be male, older, have a history of criminal charges, risky cannabis use, higher level of depression, poorer social functioning, greater disability and economic hardship, and a more advanced stage of mental illness than those engaged in education, training or work. Demographics such as postsecondary education, immigrant background and indigenous background, were not significantly associated with NEET status in this sample.

Conclusions: One in five young people seeking help for mental health problems were not in any form of education, employment and training. The commonly observed risk factors did not appear to influence this association, instead, behavioural factors such as criminal offending and cannabis use appeared to require targeted intervention.

\section{Strengths and limitations of this study}

- This study is one of the first to examine the prevalence of NEET ('Not in Education, Employment or Training') status in young Australians seeking help for mental health problems. It highlights that NEET rates in such youth $(19 \%)$ are higher than that found in general population studies of Australian youth $(11 \%)$.

- This study identified that NEET youth are more likely to be older males with a history of criminal offending as well as risky cannabis use. Not surprisingly, NEET youth reported greater levels of economic disadvantage and poorer social and occupational functioning. NEET youth were also more likely to have higher levels of depression and be in a more advanced stage of mental illness.

- Although this study is a cross-sectional cohort analysis, it exemplifies that one in five young people presenting to mental health services are likely to be NEET. Furthermore, previously identified demographic associations were not significantly associated with NEET status in this sample. Instead, behavioural factors such as criminal offending and cannabis use appear to require targeted interventions if the aim is to restore role functioning.

- This study was only able to identify $11 \%$ of the variance in NEET status. This strongly suggests that there are a range of other important factors that need to be investigated before NEET status is fully understood in this vulnerable group.

\section{BACKGROUND}

Participating in education and employment is considered key to the transition to successful adult well-being. Employment and education provides both manifest (eg, income) and latent (eg, time structure, social contact, sharing of common goals, status and activity, social and occupational support) benefits to an individual. ${ }^{1}$ Individuals with low 
educational attainment and/or limited employment experience a greater likelihood of social exclusion, ${ }^{2}$ disability and isolation, in addition to the impacts of low income: poorer quality of life, more illness and disease, ${ }^{3}$ decreased access to healthcare, increased levels of psychological distress, and maladaptive lifestyle behaviours such as substance misuse ${ }^{4-6}$ and criminal activity. ${ }^{7}$ Chronic unemployment is associated with severe levels of disadvantage and carries a significant economic cost to both the individual and society including lost earnings and taxes, as well as the increased burden on welfare and healthcare systems. $^{8}$

Adolescence and early adulthood is a crucial period in which skill development and social roles are initiated. Young people who are 'Not in Education, Employment or Training' $(\mathrm{NEET})^{5}$ are important to clinicians, policymakers and researchers as this signifies an absolute disengagement from both the labour market and a major avenue of human development. Currently, the large majority of NEET statistics are compiled by the Organisation for Economic Co-operation and Development (OECD) who provide annual comparisons of NEET rates among general youth populations in different countries. Since the onset of the global financial crisis (mid 2007), NEET rates among young people have increased considerably. ${ }^{9}$ In 2011, the NEET rate among Australian youth was $11 \%:{ }^{10}$ higher than the rate for the Netherlands and Denmark (approximately 5\%) but lower than those countries heavily affected by the financial crisis, such as Greece and Spain (approximately 18\%) and those outside the European Union, for example, Israel and Turkey (approximately 30\%). While the direct causal path for NEET status has not yet been determined, longitudinal studies conducted in the UK have demonstrated that NEET status at the age of 16 years predicts NEET status at the age of 18 years $^{11}$ and is a strong predictor of chronic unemployment in adulthood. ${ }^{12}{ }^{13}$ However, the precise risk factors and trajectories of NEET status in young people remain unclear.

In population studies, certain traits are over-represented among NEET youth. The key correlates identified to date tend to be demographic and social factors; specifically, socioeconomic status, ethnic and immigration background, parental factors (eg, occupation, educational attainment, divorce, parental unemployment), living arrangements (eg, not living with either parent, homelessness), negative school experiences (eg, low educational attainment, bullying, persistent truancy, expulsion and suspension, conduct and behavioural problems, learning difficulties) and crime. ${ }^{14-16}$ Additionally, the likelihood of being NEET increases with age and is reported as being more common among females, ${ }^{10}{ }^{17}$ although some samples report higher rates among males. ${ }^{16}$ These risk factors are derived from routinely collected information in social insurance and census databases to determine NEET status. In most cases, very little attention is paid to health or disability factors. Given that mental ill health is the primary cause of disability among people in OECD countries $^{18} \quad 19$ addressing NEET status among young people with mental illness is a key concern. ${ }^{20}$

Importantly, young people often exhibit substantial levels of disability prior to the complete manifestation of a mental disorder, reflecting either the putative prodrome of an illness ${ }^{21} 22$ or the consequence of disengagement from employment and education. ${ }^{23}$ A range of youthfocused services, such as headspace in Australia, have been established to improve clinical outcomes; however, these services were also predicated on the notion that investment in early treatment and selective prevention would produce long-term socioeconomic savings. ${ }^{24}$ The National Mental Health Commission (2013) recommended that improving social participation should also be a key outcome of such services, suggesting that clinical care must now focus on improvements beyond symptomatology. Currently, most knowledge about improving social functioning in this area is derived from studies of those with early psychosis and severe mental illness (eg, IPS: Individual Placement and Support for early psychosis) $;^{25}$ however, the large majority of youth presenting to headspace experience chronic or recurrent mood, anxiety and substance abuse disorders. ${ }^{20}$ In order to best target current and future primary health services, it is important to understand the risk profile of NEET among young people who are seeking help from these services. Such knowledge might help improve service delivery, providing opportunities for the services to intervene in the other life domains, such as employment and training, which are negatively affected by mental illness.

This study aimed to explore the prevalence of NEET status in a cross-section of young adults seeking help at a primary mental healthcare service. We wished to determine which non-clinical and clinical factors were associated with being NEET. Given that male and female youth often present with different symptom and behavioural profiles, ${ }^{22}$ this study also aimed to determine whether the associations with NEET status were moderated by gender. By attempting to profile those who are NEET, treatment and prevention strategies can be modified accordingly.

\section{METHOD}

\section{Sample}

Between January 2011 and August 2012, all young people aged between 12 and 25 years who presented to one of the four headspace clinics in Sydney and Melbourne (with varied demographic catchment areas) were approached for participation in a longitudinal cohort study evaluating the course of psychiatric disorders among young people, described in full elsewhere. ${ }^{26}$ Established by the Australian Government in 2006, headspace centres provide youth-focused mental health and general health services, drug and alcohol services, and vocational assistance to young people aged 12-25 years. There is direct access with no need for a clinician referral and no specific catchment area. There are currently 
55 centres located nationally, the four in this study being among the first established. The most common reasons for attendance at headspace are mental health problems, primarily anxiety and depressive symptoms, often in the context of psychosocial issues such as relationship conflict with family and peers. ${ }^{27}$ As headspace focuses on both mental health and early intervention, young people may present for care with varying illness severity (eg, from subthreshold symptoms to chronic disorders, mild to severely impaired social functioning) across a range of mental health problems. ${ }^{22}$ Individuals with a clinician-determined intellectual disability, acute suicidality or those without fluent English were not invited to participate. A total of 802 participants were recruited. To ensure consistency with OECD descriptions of NEET status $^{28}$ and compulsory education age in Australia, participants aged below 15 years $(n=106)$ were excluded from this study (final $\mathrm{N}=696$ ).

\section{Procedure}

After the individual's initial clinical assessment, consenting participants were contacted by a research assistant (RA) via telephone or in person to discuss the nature and aims of the research. Participants provided written informed consent. Participants were assessed by RAs who held graduate degrees in psychology using a structured interview consisting of the clinical measures outlined below. RAs were trained in the use of the structured interview and achieved an inter-rater reliability score of at least 0.8 on each of the interviewer-rated clinical measures before recruitment started. After the interview each participant was provided an iPad or laptop for the completion of the self-report measures. This process took approximately $1-2 \mathrm{~h}$ to complete. Participants received a $\$ 20$ gift voucher for reimbursement.

\section{Measures}

NEET status

Using questions from the Australian Bureau of Statistics (ABS) 2006 Census $^{29}$ participants reported if they were currently in any education, training or employment (yes/no) and how many hours per week they participated. Participants were also asked whether they had worked for payment or profit in the past month to which answers were given as: (1) worked full time, (2) worked part-time or (3) did not have a job for which I received payment. To capture those who had completely disengaged from education and employment, individuals reporting that they were 'Not in any type of Education, Employment or Training in the past month' were categorised as NEET, regardless of their volunteering roles, caring roles or parenting roles.

\section{Demographics}

Participants' age, gender, immigration background, postsecondary education, indigenous background, economic hardship, criminal charges and government assistance were assessed using self-report. To allow for comparison with other national and international NEET data, age was dichotomised: 15-19 vs 20-25 years. Immigration background participants not born in Australia or those with one or both parents born overseas were classified as being of an 'immigrant background'. Post-secondary education achieved by participants (none versus trade, apprenticeship, certificate, diploma, university degree). Indigenous background those who identified as being Aboriginal, Torres Strait Islander or Maori. Economic hardship: ABS questions assessing a reported inability of an individual or their family to pay a household expense, or the deployment of dissaving behaviour such as borrowing money to do so in the previous 3 months. Criminal charges participants reported the number and nature (eg, assault, property damage, theft/ burglary, drug use/manufacture/possession, other) of criminal charges they had ever faced by the police. Government benefits participants were asked to report whether they had received any government benefits in the past 3 months (eg, Youth Allowance, Disability Support Pension, Newstart, Other). Location of service The location of the headspace service attended by participants was recorded by administration and categorised as either 'Sydney, NSW' or 'Melbourne, Victoria.

\section{Psychological and clinical risk factors}

Substance misuse participants' alcohol, cannabis and tobacco misuse were assessed in the clinician interview using the WHO Alcohol, Smoking and Substance Involvement Screening Test (WHO-ASSIST) ${ }^{30}$ which provides a category of risk for a range of drugs including tobacco, alcohol and cannabis based on the questionnaire items numbered 2 to 7 . For cannabis and tobacco, substance involvement scores greater than 3 indicated 'at risk' participants and for alcohol, scores greater than 10. 'At risk' of misuse individuals are at risk of, or already are, experiencing health, social, financial, legal and relationship problems resulting from their substance use, and the possibility of dependence. Childhood onset disorder participants' recall of a prior diagnosis of a disorder in childhood such as hyperactivity, autism, attention deficit disorder or conduct disorder. Depressive symptoms assessed using the clinician rated Quick Inventory of Depressive Symptomatology (QIDS- $\left.\mathrm{C}_{16}\right)^{31}$ which examined the presence, during the previous 7 days, of the major DSM-IV (Diagnostic and Statistical Manual of Mental Disorders, Fourth edition) diagnostic symptoms of depression rated on a four-point Likert scale, combined to provide total scores ranging 0-27. Anxiety was assessed by self-report using the Generalised Anxiety Disorder (GAD-7) questionnaire. ${ }^{32}$ Clinical stage was operationalised as a clinicianrated indicator of the severity and chronicity of mental illness experienced by participants. In accordance with the criteria established by the clinical staging model ${ }^{33}$ participants were classified as either 'Stage 1' (non-specific symptoms or attenuated syndrome) or 'Stage 2+' (first episode of discrete disorder or persistent, recurrent mental illness). Participants' level of social and neurocognitive functioning are also considered when determining clinical 
stage. Staging decisions were based on the results of the clinical interview with any discrepancies resolved in consensus meetings with RAs and clinical supervisors.

\section{Functioning measures}

Disability using the 12 item self-report WHODAS12 questionnaire, ${ }^{34}$ participants self-rated their difficulty performing daily life activities during the past 30 days. Global scaled scores range from 0 to 48 with higher scores indicating a moderate to severe level of disability. Social and occupational functioning assessed by the interviewer using the clinician-rated Social and Occupational Functioning Assessment Scale (SOFAS) which allocated an overall functioning score ranging between 0 and 100 , with higher score suggesting a superior level of functioning.

\section{Analysis}

This investigation used cross-sectional baseline data from a longitudinal cohort study. All statistical analyses were conducted in SPSS V.22. Group differences between NEET and non-NEET participants were assessed using t tests and simple logistic regressions for categorical variables. Levene's tests for equal variances were conducted for the continuous variables, for which none violated any assumptions. Owing to the number of univariate analyses conducted, an $\alpha$ correction using the Bonferroni method was made: the adjusted $\alpha$ level for statistical significance was determined to be $\mathrm{p}<0.003$. To examine the independent associations of NEET status, a hierarchical logistic regression was conducted: NEET status was entered as the dichotomous-dependent variable. All variables achieving significance at $\mathrm{p}<0.003$ in the univariate analysis were included in the first step of multivariate analysis except for self-reported disability and social and occupational functioning due to the circularity with NEET status. To control for the relationship between criminal charges and income, economic hardship was entered as a confounder. The interaction terms for gender were subsequently added in the second model. Continuous variables were centred before interaction terms were created and only centred variables are included in the multivariate analyses. Only models with non-significant Hosmer-Lemeshow goodnessof-fit tests were included.

\section{RESULTS}

\section{Participants}

In this sample of help-seeking young adults $(\mathrm{N}=696$, $\mathrm{M}_{\text {age }}=19$ years, $\mathrm{SD}=2.8$, age range $15-25$ years, $68 \%$ female), 58\% ( $\mathrm{n}=404)$ attended headspace Sydney, $42 \%$ $(\mathrm{n}=291)$ had one or both parents born overseas; $19 \%$ $(\mathrm{n}=129)$ had a postsecondary education; 4\% $\quad(\mathrm{n}=28)$ were indigenous; 32\% ( $\mathrm{n}=226)$ experienced economic hardship, and $17 \% \quad(\mathrm{n}=117)$ reported one or more instances of perceived discrimination. A total of 70 participants $(10 \%)$ had a history of criminal offending with 132 counts of crime reported: $36 \%(n=47)$ theft/burglary, $19 \% \quad(\mathrm{n}=25)$ were physical assault, $16 \% \quad(\mathrm{n}=21)$ property damage, $14 \%(\mathrm{n}=19)$ were drug related, $15 \%$ $(n=20)$ were 'other'. In the current sample, $19 \%$ $(\mathrm{n}=133)$ were classified as at risk for alcohol, $50 \%$ $(\mathrm{n}=346)$ for tobacco and $29 \%(\mathrm{n}=199)$ for cannabis. The mean symptom and functioning scores were: depression (QUIDS) 10.44 (SD 5.34, range 0-26), anxiety (GAD) 10.10 (SD 5.95, range 0-21), self-rated disability (WHODAS) 13.25 (SD 9.39, range 0-47) and SOFAS 65.33 (SD 11.61, range 30-95) with $13 \%(\mathrm{n}=91)$ reporting a child onset disorder and 13\% ( $\mathrm{n}=93)$ classified as Clinical stage 2+.

\section{NEET status}

A total of $19 \%(n=130 / 679)$ of participants were classified as NEET. Among these, 68\% $(\mathrm{n}=88 / 130)$ had received some form of government assistance in the past 3 months: $26 \%(\mathrm{n}=34)$ received youth allowance, $25 \%$ $(\mathrm{n}=32)$ received unemployed/job seekers allowance, $11 \%$ $(n=14)$ received the disability support pension, $8 \%(n=7)$ received a parenting payment and one participant reported receiving 'other'. NEETs were more likely to be male and aged between 20 and 25 years (see table 1 ). NEETs had higher symptom levels of depression, but not anxiety, and were more likely to be in a progressed stage of mental illness (Clinical stage 2). NEETs reported higher levels of disability, lower levels of social and occupational functioning and higher rates of economic hardship (table 1). NEETs were also more likely to have a history of criminal charges and risky cannabis use (but not alcohol or tobacco) than non-NEETs. Notably, NEET status was not associated with state location of centre, immigrant background, postsecondary education or indigenous background. In model 1 of the multivariate analysis (table 2), older age (20-25 years), gender (male), a history of criminal charges, cannabis risk and depressive symptoms were independently associated with NEET status. This model accounted for $10 \%$ of the variance in NEET status. While model 2 was significant overall, the addition of the gender interaction terms did not significantly improve the model fit. In particular, the association between depressive symptoms and NEET status was not moderated by gender. All of the associations found in model 1 remained significant, confirming that NEET status was most strongly associated with older age, being male, criminal charges and depression.

\section{DISCUSSION}

In this sample of young adults with mental health problems, nearly one in five $(19 \%)$ were not engaged in any education, employment or training. This rate is nearly twice that found among the general population of youth aged 15-24 years living in Australia (11\%, OECD 2011). In the current study, those categorised as NEET had higher symptom levels of depression and a more advanced stage of mental illness: NEETs were more likely to be male, older, have a history of criminal charges and risky cannabis use. Not surprisingly, NEET participants 
Table 1 Univariate associations with NEET status among young adults seeking help for mental health problems $(n=679)$

\begin{tabular}{|c|c|c|c|c|}
\hline & $\begin{array}{l}\text { NEET } \\
n=130(19 \%) \\
n(\%)\end{array}$ & $\begin{array}{l}\text { Non-NEET } \\
n=549(81 \%) \\
n(\%)\end{array}$ & OR $(95 \% \mathrm{Cl})$ & p Value \\
\hline Sydney & $75(58 \%)$ & 314 (57\%) & $1.02(0.69$ to 1.50$)$ & 0.92 \\
\hline Age $20-25$ years & 77 (59\%) & 206 (30\%) & 2.42 (1.64 to 3.57$)$ & 0.000 \\
\hline Male & $62(48 \%)$ & $159(29 \%)$ & 2.24 (1.51 to 3.31$)$ & 0.000 \\
\hline Immigrant background & $58(45 \%)$ & $233(42 \%)$ & $1.09(0.74$ to 1.61$)$ & 0.65 \\
\hline Indigenous background & $6(5 \%)$ & $22(4 \%)$ & 1.16 (0.46 to 2.92$)$ & 0.75 \\
\hline Criminal charges & $26(20 \%)$ & $44(8 \%)$ & 2.85 (1.68 to 4.83$)$ & 0.000 \\
\hline Postsecondary education & $22(17 \%)$ & $107(19 \%)$ & 0.84 (0.51 to 1.39$)$ & 0.50 \\
\hline Economic hardship & $54(42 \%)$ & $172(31 \%)$ & 2.15 (1.37 to 3.39$)$ & 0.001 \\
\hline Perceived discrimination & 29 (22\%) & $88(16 \%)$ & 1.94 (1.11 to 3.38$)$ & 0.02 \\
\hline Alcohol risk & $30(23 \%)$ & $100(18 \%)$ & 1.37 (0.86 to 2.17$)$ & 0.19 \\
\hline Tobacco risk & $74(57 \%)$ & $262(48 \%)$ & 1.46 (0.99 to 2.16$)$ & 0.05 \\
\hline Cannabis risk & $50(38 \%)$ & $139(25 \%)$ & 1.94 (1.29 to 2.90$)$ & 0.001 \\
\hline Child onset disorder & $27(21 \%)$ & $62(11 \%)$ & $2.06(1.24$ to 3.40$)$ & 0.01 \\
\hline \multirow[t]{2}{*}{ Clinical stage $2+$} & $35(27 \%)$ & $56(10 \%)$ & 3.20 (1.99 to 5.16$)$ & 0.000 \\
\hline & M (SD) & M (SD) & MD (95\% Cl) & p Value \\
\hline Anxiety score & $11.35(6.16)$ & $9.81(5.87)$ & $1.54(0.41$ to 2.68$)$ & 0.01 \\
\hline Depression score & $12.62(5.56)$ & $9.89(5.10)$ & 2.72 (1.73 to 3.72$)$ & 0.000 \\
\hline Self-rated disability & $16.19(9.94)$ & $12.55(9.12)$ & 3.65 (1.86 to 5.43$)$ & 0.000 \\
\hline SOFAS & $56.14(10.40)$ & $67.67(10.80)$ & $-11.53(-13.59$ to -9.48$)$ & 0.000 \\
\hline
\end{tabular}

Bold $=\mathrm{p}<0.003$.

NEET, Not in Education, Employment or Training; SOFAS, Social and Occupational Functioning Assessment Scale (range 0-100).

had lower levels of social and occupational functioning, higher levels of disability and experienced greater economic hardship compared to non-NEETs. Interestingly, demographic factors commonly found to be associated with NEET status in routine population statistics ${ }^{6}$ such as postsecondary education, immigration background, indigenous background were not significantly associated with NEET status in this sample. This suggests that although such factors may be important for young adults with reasonable mental health, these factors are less important in this restricted sample. Alternatively, mental ill health and substance abuse may mediate or confound the impact of these demographic risks. Overall, the results find that young adults with mental health problems, particularly older males, are at high risk of being NEET and may experience a level of vocational and educational disability that is on par with some of the most disadvantaged OECD nations in the world. ${ }^{5}$

In the current study, males were more likely to be NEET than females. This is somewhat inconsistent with OECD data which generally reports a higher prevalence of NEET status among women. ${ }^{10} 1728$ We suspect that

Table 2 Multivariate associations with NEET status among young adults seeking help for mental health problems ( $\mathrm{n}=526)$

\begin{tabular}{|c|c|c|c|c|c|c|c|c|}
\hline & \multicolumn{4}{|c|}{$\begin{array}{l}\text { Base model } \\
\text { C-S R } R^{2}=0.10^{\star}\end{array}$} & \multicolumn{4}{|c|}{$\begin{array}{l}\text { +Gender interaction terms } \\
\text { C-S } R^{2}=0.11^{*}\end{array}$} \\
\hline & B (SE) & OR & $95 \% \mathrm{Cl}$ & p Value & B (SE) & OR & $95 \% \mathrm{Cl}$ & p Value \\
\hline Male & $0.76(0.27)$ & 2.13 & 1.26 to 3.60 & 0.005 & $1.50(0.46)$ & 4.50 & 1.81 to 11.16 & 0.001 \\
\hline Age $20-25$ years & $0.77(0.26)$ & 2.16 & 1.30 to 3.60 & 0.003 & $1.04(0.34)$ & 2.82 & 1.44 to 5.51 & 0.002 \\
\hline Economic hardship & $0.47(0.27)$ & 1.60 & 0.95 to 2.69 & 0.080 & $0.45(0.27)$ & 1.57 & 0.93 to 2.68 & 0.095 \\
\hline Criminal charges & $0.81(0.35)$ & 2.24 & 1.13 to 4.42 & 0.020 & $1.36(0.51)$ & 3.84 & 1.43 to 10.34 & 0.008 \\
\hline Cannabis risk & $0.20(0.27)$ & 1.22 & 0.72 to 2.05 & 0.082 & $0.57(0.35)$ & 1.78 & 0.90 to 3.49 & 0.100 \\
\hline Depression score & $0.10(0.02)$ & 1.10 & 1.05 to 1.15 & 0.000 & $0.07(0.03)$ & 1.07 & 1.01 to 1.14 & 0.025 \\
\hline Age groupxgender & & & & & $-0.52(0.52)$ & 0.60 & 0.22 to 1.65 & 0.318 \\
\hline Criminal charges $\times$ gender & & & & & $-0.97(0.70)$ & 0.38 & 0.10 to 1.47 & 0.161 \\
\hline Cannabis risk $\times$ gender & & & & & $-0.92(0.55)$ & 0.39 & 0.13 to 1.17 & 0.094 \\
\hline Depression×gender & & & & & 0.07 (0.05) & 1.07 & 0.97 to 1.18 & 0.191 \\
\hline \multicolumn{9}{|c|}{$\begin{array}{l}\text { Bold=p<0.05. Base model: Nag } R^{2}=0.16,-2 \mathrm{LL}: 428.76, \text { model } \chi^{2}(6)=52.67, p<0.001 \text {, step } 2 \text { (+Gender interaction terms): Nag } \mathrm{R}^{2}=0.18, \\
-2 \mathrm{LL}: 419.89 \text {, model } \chi^{2}(10)=61.54, p<0.001, \Delta \chi^{2}(4)=8.87, p=0.064 . \\
\text { * } \mathrm{p}<0.001 . \\
\text { NEET, Not in Education, Employment or Training. }\end{array}$} \\
\hline
\end{tabular}


this is related to the nature of the data used to ascertain NEET status on a population level by OECD countries. More often than not, NEET status includes those who partake in care giving roles such as full-time parenting. As females tend to adopt such roles in most countries, it is difficult to determine which gender is truly disengaged from a meaningful role. In countries which do account for this (eg, Scandinavia), sex differences in NEET status are either not as profound, or are more common in men. ${ }^{17}$ Furthermore, longitudinal cohorts from the UK ${ }^{11}$ consistently report a higher likelihood of males being NEET. This highlights the current difficulties in comparing NEET rates and supports the need for a more cohesive approach to examining NEET status.

Of the symptom factors, depression was significantly associated with NEET status. The main association is not surprising as depressed individuals report greater restlessness, trouble concentrating and a failure to consider or plan for the future. ${ }^{35}$ Those with depression often withdraw from social activities and relationships, decreasing the size of their social networks and severing relationships which may offer support and enhance occupational functioning. Conversely, disengagement is also likely to lead to worse mood: being NEET may exacerbate depressive symptoms, leading to greater social isolation and diminished role functioning. Although not significant, a greater proportion of those who were NEET also reported higher rates of perceived discrimination. Understanding the links between mental illness, in particular depression, stigma and role functioning is important for the development of both clinical treatments and social programmes attempting to improve role functioning. However, the current findings may reflect a sample bias: mental health services such as headspace may be capturing those NEETs who are experiencing depressive symptoms rather than those NEET who are not.

Criminal offending and cannabis use were significantly associated with NEET status. The latter is not surprising as substance use often emerges as a risk factor for both poorer functioning and clinical symptoms in studies of youth. ${ }^{36-38}$ As demonstrated by the current study, cannabis use may place young adults at greater risk of becoming NEET, although a trend also appears for tobacco use. As poor physical health is associated with these substances, youth focused health services must seriously account for the impact of substance use on treatment outcomes and role functioning. Innovative treatment approaches are needed as many young adults are reluctant to engage in interventions for substance use. Given the widely published link between youth unemployment and crime, ${ }^{39}$ the association between criminal offending and NEET status were also not unexpected. The precise direction of causality between these variables cannot be determined by the current study: whether criminal offending is a consequence of economic hardship (as a number of criminal offences were for theft),${ }^{40}$ or representative of greater social adversity or other underlying personality traits, is unknown. Regardless, these results signify that such behaviour limits the capacity for role functioning in young adults. These findings suggest that if the aim of services like headspace is to increase role functioning in young adults with mental health problems, simply focusing on ameliorating symptoms, predominantly anxiety and depression, may not be the best approach. ${ }^{24}$

\section{Limitations}

This study is based on a cross-sectional sample of selfselected, help-seeking young adults with mental health problems. The findings may be limited by such selection bias although the overall level of NEET status and the gender differences in the sample are similar to those reported in the national headspace dataset. ${ }^{27}$ The current study did not include a control group and as such, no comparisons can be made to youth without mental health concerns or those not seeking help. While parenting or caring roles were not separated from NEET status in the current study, 14 participants (7 of which were NEET) received a parental payment from the government, suggesting that $2 \%$ of the total sample were parents. As females are more likely than males to adopt caring roles in the absence of education, employment or training, ${ }^{11}$ future investigation may benefit from focusing on the nature of such responsibilities within similar samples of NEETs. Importantly, different associations for NEET status may be found among young adults who present to other services (eg, justice and criminal systems) and among samples that are more culturally and ethnically diverse. As the final regression model only accounted for $11 \%$ of the variance in NEET status, a range of other factors need to be considered including the family unit, cognitive impairment ${ }^{41}$ and occupational aspirations. ${ }^{42}$ Future research would benefit from determining the range of other factors, both clinical and non-clinical, including the economic environment that may be related to NEET status in young adults with mental health concerns. Research with a longitudinal focus would help untangle the direction of causality and outline the trajectories of NEET status in youth.

\section{CONCLUSIONS}

This study confirms that among young adults with mental health problems, NEET status is highly prevalent. ${ }^{20}$ The factors identified in this study suggest that when designing clinical or policy initiatives to improve role functioning among youth with mental health problems it is necessary to consider a range of clinical and non-clinical factors. Traditional clinical approaches which focus on symptoms may need to be augmented and tailored in help-seeking young adults. Multidisciplinary approaches to offending behaviour and substance use are also required. Furthermore, it appears that males with mental health concerns are at considerable risk of being NEET and that headspace appears to be capturing these men at a 
later age, in a more progressed stage of mental illness and experiencing greater social dysfunction when compared to females. ${ }^{27}$ Collaborative and integrated service centres such as headspace are more likely to be effective in achieving their policy objectives in the functional and economic domains by further understanding the groups most at risk and allocating resources appropriately. However, the high proportion of youth presenting as NEET suggests that these 'early intervention services' are, in many cases, not 'early' enough.

\section{Author affiliations}

${ }^{1}$ Brain and Mind Research Institute, The University of Sydney, Sydney, New South Wales, Australia

${ }^{2}$ Centre for Forensic Behavioural Science, Swinburne University of Technology, Melbourne, Victoria, Australia

${ }^{3}$ Orygen Research Centre, Centre for Youth Mental Health, University of Melbourne, Parkville, Victoria, Australia

${ }^{4}$ Institute of Neuroscience, Newcastle University, Newcastle, UK

${ }^{5}$ The University of Sydney Business School, Sydney, New South Wales, Australia

${ }^{6}$ Institute of Brain, Behaviour and Mental Health, University of Manchester, UK

Contributors The study was designed and conducted by PDM, IBH, NG, DFH, $R P, E K, A R Y, A J G$ and EMS. The analysis of data and interpretation was conducted by BO, K-LF and NG. The paper was prepared by BO, NG and K-LF and critically revised by PDM, IBH, JS, DFH, RP, EK, ARY, EMS, AJG and JB. The other investigators on the Transitions Study were A. Jorm, L. Phillips, S. W. Wood, A. Mackinnon, A. Kenyon, L. Mundy, A. Nichles, A, Scaffidi, D. Spiliotacopoulos, L. Taylor, J.P.Y Tong, S. Wiltink, and N. Zmicerevska. This study was conducted at Brain and Mind Research Institute, University of Sydney and Orygen Youth Health Research Centre, Melbourne.

Funding The study was supported by an NHMRC Program Grant (ID: 566529).

Competing interests IBH is a Board Member of Psychosis Australia Trust. From 2012, he has been a Commissioner in Australia's new National Mental Health Commission. He was until January 2012 a director of headspace: The National Youth Mental Health Foundation. IBH was previously chief executive officer (until 2003) and clinical adviser (until 2006) of Beyondblue, an Australian National Depression Initiative. He is supported principally for clinical research in depression and health services and population health initiatives related to anxiety and depression by an NHMRC Australian Medical Research Fellowship (2007-2012) and now by an NHMRC Senior Principal Research Fellowship (2013-2017). He has led projects for health professionals and the community supported by governmental, community agency and pharmaceutical industry partners (Wyeth, Eli Lily, Servier, Pfizer, AstraZeneca) for the identification and management of depression and anxiety. He has received honoraria for presentations of his own work at educational seminars supported by a number of non-government organisations and the pharmaceutical industry (including Pfizer, Servier and Astra Zeneca). He has served on advisory boards convened by the pharmaceutical industry in relation to specific antidepressants, including nefazodone, duloxetine and desvenlafaxine. He leads an investigator-initiated study of the effects of agomelatine on circadian parameters (supported in part by Servier but also by other NHMRC funding) and has participated in a multicentre clinical trial of agomelatine effects on sleep architecture in depression and a Servier-supported study of major depression and sleep disturbance in primary care settings. In addition to national and international government-based grant bodies, investigator-initiated mental health research at the BMRI he has been supported by various pharmaceutical manufacturers (including Servier and Pfizer) and not-for-profit entities (including the Heart Foundation, beyondblue and the BUPA Foundation).

Ethics approval Ethics was granted by the Human Research Ethics Committees at the University of Melbourne and the University of Sydney.

Provenance and peer review Not commissioned; externally peer reviewed.
Data sharing statement The data set for this study is not currently publically available; however, all statistical code can be reviewed by contacting the corresponding author bridianne.odea@sydney.edu.au.

Open Access This is an Open Access article distributed in accordance with the Creative Commons Attribution Non Commercial (CC BY-NC 4.0) license, which permits others to distribute, remix, adapt, build upon this work noncommercially, and license their derivative works on different terms, provided the original work is properly cited and the use is non-commercial. See: http:// creativecommons.org/licenses/by-nc/4.0/

\section{REFERENCES}

1. Creed PA, Macintyre SR. The relative effects of deprivation of the latent and manifest benefits of employment on the well-being of unemployed people. J Occup Health Psychol 2001;6:324-31.

2. Wanberg CR. The individual experience of unemployment. Annu Rev Psychol 2012;63:369-96.

3. Mustard CA, Bielecky A, Etches J, et al. Mortality following unemployment in Canada, 1991-2001. BMC Public Health 2013;13:441.

4. Bynner J, Parsons S. Social exclusion and the transition from school to work: The case of young people not in education, employment, or training (NEET). J Vocational Behav 2002;60:289-309.

5. Eurofound. NEETs-young people not in employment, education or training: characteristics, costs and policy responses in Europe. Luxembourg: Publications Office of the European Union, 2012.

6. Pemberton S. Tackling the NEET generation and the ability of policy to generate a 'NEET' solution-evidence from the UK. Environ Plann C Gov Policy 2008;26:243-59.

7. Nardi B, Arimatea E, Giunto P, et al. Not Employed, in Education or Training (NEET) adolescents with unlawful behaviour: an observational study. J Psychopathol 2013;19:42-8.

8. Coles B, Godfrey C, Keung A, et al. Estimating the life-time cost of NEET: 16-18 year olds not in Education, Employment or Training. York: University of York, 2010.

9. International Labor Office. Global employment trends for youth. Geneva International Labor Office, 2012.

10. OECD. Education at a glance 2013: OECD indicators. OECD Publishing, 2013.

11. National Statistics of the United Kingdom. Youth cohort study and the longitudinal study of young people in England: the activities and experiences of 18-year-olds-England 2009. National Statistics, Department for Education, 2010.

12. Franzen EM, Kassman A. Longer-term labour-market consequences of economic inactivity during young adulthood: a Swedish national cohort study. J Youth Stud 2005;8:403-24.

13. Quintini G, Martin J, Martin S. The changing nature of the school-to-work transition process in OECD countries. Institute for the Study of Labour (IZA), 2007.

14. Cassen R, Kingdon G. Tackling low educational achievement. York, UK: Joseph Rowntree Foundation, 2007.

15. Farrington DP, Welsh BC. Saving children from a life of crime: early risk factors and effective interventions. New York: Oxford University Press, 2006.

16. Stoneman P, Thiel D. NEET in Essex: a review of the evidence. Colchester: University of Essex, 2010.

17. OECD. Education at a glance 2012: OECD indicators. OECD Publishing, 2012.

18. Merikangas KR, Nakamura EF, Kessler RC. Epidemiology of mental disorders in children and adolescents. Dialogues Clin Neurosci 2009;11:7-20.

19. Hickie IB, Koschera A, Davenport TA, et al. Comorbidity of common mental disorders and alcohol or other substance misuse in Australian general practice. Med J Aust 2001;175:S31-6.

20. Scott J, Fowler D, McGorry PD, et al. Adolescents and young adults who are not in employment, education, or training. BMJ 2013;347: f5270.

21. Hamilton BA, Naismith SL, Scott EM, et al. Disability is already pronounced in young people with early stages of affective disorders: data from an early intervention service. J Affect Disord 2011;131:84-91.

22. Scott EM, Hermens DF, Glozier N, et al. Targeted primary care-based mental health services for young Australians. Med $J$ Aust 2012;196:136-40.

23. Maguire S, Cockx B, Dolado J, et al. Youth unemployment. Intereconomics 2013;48:196-235.

24. McGorry PD. The specialist youth mental health model: strengthening the weakest link in the public mental health system. Med J Aust 2007;187(7 Suppl):S53-6. 
25. Killackey E, Jackson HJ, McGorry PD. Vocational intervention in first-episode psychosis: individual placement and support v. treatment as usual. Br J Psychiatry 2008;193:114-20.

26. Purcell R, Jorm AF, Hickie IB, et al. Transitions study of predictors of illness progression in young people with mental ill health: study methodology. Early Interv Psychiatry 2013. doi:10.1111/eip.12079

27. Rickwood DJ, Telford NR, Parker AG, et al. Headspace-Australia's innovation in youth mental health: who are the clients and why are they presenting? Med J Aust 2014;200:108-11.

28. OECD. NEET rates among youth in OECD countries: percentage of population aged 15-24. OECD Employment Outlook 2012. OECD Publishing, 2012

29. Trewin D. How Australia takes a census. Canberra: Australian Bureau of Statistics, 2006.

30. Humeniuk R, Ali R. Validation of the alcohol, smoking and substance involvement screening test (ASSIST). Addiction 2008;103:1039-47.

31. Rush AJ, Trivedi MH, lbrahim HM, et al. The 16-Item Quick Inventory of Depressive Symptomatology (QIDS), clinician rating (QIDS-C), and self-report (QIDS-SR): a psychometric evaluation in patients with chronic major depression. Biol Psychiatry 2003;54:573-83.

32. Spitzer RL, Kroenke K, Williams JB, et al. A brief measure for assessing generalized anxiety disorder: the GAD-7. Arch Intern Med 2006;166:1092-7.

33. Hickie IB, Scott EM, Hermens DF, et al. Applying clinical staging to young people who present for mental health care. Early Interv Psychiatry 2013;7:31-43.
34. Ustün TB, Chatterji S, Kostanjsek N, et al. Developing the World Health Organization disability assessment schedule 2.0. Bull World Health Organ 2010;88:815-23.

35. Dopheide JA. Recognizing and treating depression in children and adolescents. Am J Health Syst Pharm 2006;63:233-43.

36. Glozier N, O'Dea B, McGorry PD, et al. Delayed sleep onset in depressed young people. BMC Psychiatry 2014;14:33.

37. Riehman KS, Stephens RL, Schurig ML. Substance use patterns and mental health diagnosis among youth in mental health treatment: a latent class analysis. J Psychoactive Drugs 2009;41:363-8

38. Schwinn TM, Schinke SP, Trent DN. Substance use among late adolescent urban youths: mental health and gender influences. Addict Behav 2010;35:30-4.

39. McAra L, McVie S. Youth crime and justice: key messages from the Edinburgh Study of Youth Transitions and Crime. Criminol Crim Justice 2010;10:179-209.

40. Altindag DT. Crime and unemployment: evidence from Europe. Int Rev Law Econ 2012;32:145-57.

41. Lee RS, Hermens DF, Redoblado-Hodge MA, et al.

Neuropsychological and socio-occupational functioning in young psychiatric outpatients: a longitudinal investigation. PLOS ONE 2013;8:e58176

42. Yates S, Harris A, Sabates R, et al. Early occupational aspirations and fractured transitions: a study of entry into 'NEET' status in the UK. J Soc Policy 2011;40:513-34. 